\title{
Compulsory community service for dentists - Opportunity for meaningful reform
}

SADJ May 2021, Vol. 76 No. 4 p201 - p206

ML Machete', LN Makwakwa², PD Moipolai ${ }^{3}$, DP Motloba ${ }^{4}$

\section{ABSTRACT}

\section{Introduction}

Previous studies indicate that the delivery of the compulsory community service (CS) programme was far from the intended objectives. It is plausible that the intended vision of the programme for the young graduates to “...develop skills, acquire knowledge, behaviour patterns and critical thinking that would help in their professional development and future careers." may not be realizable.

\section{Objective}

This study evaluated the extent to which CS programme enabled CS dentists to develop clinical skills.

\section{Methods}

A national cross-sectional study was undertaken on CS dentists. Adapted visual analogue scale (VAS) assessed the frequency of work performed and levels of skills or competency acquired.

\section{Results}

A total of $217 / 235$ dentists participated, (response rate of $92.34 \%)$. The clinical work undertaken and skills/competence acquired were positively correlated; [Mean (SD) = 1.10 (0.326), 1.10 (0.359); $r=0.945, p=<0.000, n=217$ ]

\section{Author affiliations:}

1. Motimedi L Machete: BDS (UL), MDS (SMU), Registrar (MDent), Department of Community Dentistry, School of Oral Health Sciences, Sefako Makgatho Health Sciences University (SMU), GaRankuwa, South Africa.

ORCID Number: 0000-0002-0218-8428

2. Nokukhanya L Makwakwa: MPH (UL), M Dent (Comm Dent) (SMU), Specialist Community Dentistry, Department of Community Dentistry, School of Oral Health Sciences, Sefako Makgatho Health Sciences University (SMU), Ga-Rankuwa, South Africa. ORCID Number: 0000-0001-5669-795X

3. Pusetso D Moipolai: MDent (Pros)(Wits) MEd (Wits), Head of Clinical Department, Department of Prosthodontics, School of Oral Health Sciences, Sefako Makgatho Health Sciences University (SMU), Ga-Rankuwa, South Africa. ORCID Number: 0000-0003-0388-5898

4. Pagollang D Motloba: MDent (Comm Dent) (Medunsa), MBL (UNISA), Head, Department of Community Dentistry. School of Oral Health Sciences, Sefako Makgatho Health Sciences University (SMU), Ga-Rankuwa, South Africa.

ORCID Number: 0000-0003-1379-7576

Corresponding author: Motimedi L Machete

Department of Community Dentistry, School of Oral Health Sciences,

Sefako Makgatho Health Sciences University (SMU), Ga-Rankuwa, South Africa.

Email: lesley.machete@smu.ac.za

Author contributions:

1. Motimedi L Machete: Principal author - $40 \%$

2. Nokukhanya L Makwakwa: Second author - $20 \%$

3. Pusetso D Moipola: Third author - $10 \%$

4. Pagollang D Motloba: Fourth author - $30 \%$ respectively. This finding validates the associated loss of skills and competence because of lack of clinical exposure during CS. Specialised dental procedures were never or rarely performed during CS (89.5\%). Similarly the level of skills acquired during CS was minimal.

\section{Conclusion}

CS in its present form disrupts continuing education and the development of learning and clinical skills. These cohorts of dentists have entered independent practice less prepared; may fail to provide quality care to the public. The CS programme is regressive, and requires urgent review and reform.

\section{Keywords}

Compulsory community services, competence, clinical skills, scope of practice, specialised dentistry.

\section{INTRODUCTION}

The moral and legal basis for the introduction of compulsory community service (CS) for health professionals is undebatable. The passed legislation (Republic of South Africa, 1997) ${ }^{1}$ saw medical professionals deployed across the country especially in rural and remote health centres in the country. ${ }^{3}$ For dentists, the first cohort was placed in July 2000. ${ }^{4}$ It was envisaged that "...the young graduates would develop skills, acquire knowledge, behaviour patterns and critical thinking that would help in their professional development". ${ }^{2}$ Almost two decades later, only a singular study documented the experience of dentists after four years of the initiation of CS. ${ }^{6}$

It remains unclear whether this programme has achieved its intended goals or not. The evaluation of CS reveals a dichotomy of views, with proponents hailing the programme as successful in reducing oral health inequity and increasing access to care. ${ }^{6,8}$ Antagonists, assert that the programme perpetuates supervised neglect of inexperienced young doctors and dentists, which could contribute to harm of patients. ${ }^{2,6,12}$ In addition, these novice practitioners are expected to function in under resourced settings without guidance and support. ${ }^{2}$

Multiple studies have indicated that the implementation challenges remain unresolved. Reports show that provision of appropriate accommodation, support, infrastructure, materials and consumables remain inadequate. Nevertheless, health professionals continue to be successfully placed in areas of need. 
The challenges persist to date for all dentists participating in CS. Financing and allocation of adequate resources remains a serious impediment to the provision of comprehensive oral health services. Anecdotal evidence suggests that health service managers do not prioritise oral health, relegating this service to management of pain and sepsis in a majority of facilities. This status quo is a stark contradiction of the founding principles of the programme to ensure that the "... provision of health services would improve for all citizens." ${ }^{6}$ For the levels of skill and expertise acquired during training, most dentists maybe underutilised and over payed for the complexity of work they perform.

The objective of this study was to evaluate the extent to which CS provided an opportunity for dentists to undertake complex dental procedures, as per the scope of practice and training received. In other words, to what extent has CS programme enabled dentists to hone their clinical skills and competence in "specialised dentistry"? This term "specialised dentistry" is used loosely to include a set of clinical procedures that would not be routinely performed by dental therapists or oral hygienists as per their gazetted scopes of practice.

We hypothesize that despite the CS programme being well intentioned, socially justifiable and morally admirable; it remains clinically regressive to the participating dentists. Which begs the question whether the CS programme in its present form, should continue or should be reviewed and reformed to realize its objectives.

\section{MATERIAL AND METHODS}

\section{a). Study design}

A nation-wide descriptive cross-sectional study was undertaken on dentists who had completed community service in South Africa and who graduated from South African universities.

\section{Study participants}

All dentists who were deployed in CS since its inception in 2000 to 2015 were eligible to participate in the study. South Africans who completed their dental education outside the country were excluded from the study.

\section{Sample size determination}

A total of 235 participants were required for the study, based on the following assumptions: precision of 95\%, margin of error at 5\% and study effect of 15\% ${ }^{6}$ (proportion of dentists not satisfied or knowledgeable about community service). The sample size estimation was based on a finite population of approximately 3000 dentists. The four schools of dentistry in the country graduate around 50 dentists per year for 15 years, giving a total of 3000 community service dentists.

\section{Sampling and recruitment of participants}

Several strategies were used to develop a sampling frame for this study: (i) the national and provincial oral health managers provided a list of present and past CS dentists in their jurisdiction; (ii) the clinical managers and the present CS dentists reviewed and updated the information of their previous employees. (iii) The graduation lists were sought from dental schools for the period of the study. These lists were harmonised to create a comprehensive sampling frame from which participants were recruited. Given that, some contact details were missing or not current, the researchers used the snowball technique to enrol more participants into the study. Dentists were included in the study only if they consented and were willing to complete the questionnaire.

\section{Data collection}

A structured questionnaire was emailed to all participants in the updated mailing list. A follow up email was sent within two weeks to remind participants, thereby improve the response rate. The data collection tool comprised of four sections, which evaluated the demographics, the complexity at which clinical procedures were done, the perceived level of clinical skills, competence acquired, and challenges faced during CS.

For the demographic variables the response options, were Yes or No, and a Likert scale with four responses (Emphatic yes; Yes; No; and Emphatic no) for questions evaluating challenges. The participants rated frequency of clinical procedures performed and skills acquired using the adapted visual analogue scale (VAS). The VAS score ranged from zero (0) to ten (10).

The score of zero indicates the least or no intensity and ten (10), the greatest intensity. In this study, the score of zero was indicative of no clinical activity or procedures done; and no skills acquired or competence gained. The score of ten represents the greatest intensity, or full involvement in clinical activities and greatest skills acquired, resulting in attainment of competence.

For ease of interpretation, the scores for clinical activity were further categorised as follows:

- $(0-2)=$ Never/rarely.

- $(2-4)=$ Sometimes.

- $(4-6)=$ Often .

- $(6-8)=$ Very often

- $(8-10)=$ Always .

Similarly, the level of skill acquired and or competence level achieved was categorised as follows:

- $(0-2)=$ Not at all $/$ minimal

- $(2-4)=$ Slight

- $(4-6)=$ Moderate.

- $(6-8)=$ Much .

- $(8-10)=$ Greatest or much more.

\section{Data analysis}

Data were captured and cleaned in Microsoft Excel, and analysed in Statistical Package for Social Sciences (SPSS) ver.24. Measures of central tendency and dispersion were computed for the numerical variables and proportions for categorical variables. Pearson's correlation coefficient was computed to measure the relationship between the frequency at which procedures were undertaken and the level of skill or competence 
developed as a consequence. ANOVA was undertaken to assess differences in outcomes (frequency of procedures and level of skills acquired) by year of community services, gender, race, institution.

\section{RESULTS}

\section{Socio-demographic profile of participants}

A total of $217 / 235$ dentists participated in the study, giving a response rate of $(92,34 \%)$. The mean age of 32.94 (5.184), and range of 27 years (Min 23: Max 50) were recorded. The majority of participants were below 35 years of age (69.7\%), female (58.6\%), black African (78.0\%), unmarried (78.3\%) and (62.6\%) were currently employed in the public sector (Table 1).

Intensity or level at which procedures were undertaken during community service

Community service dentists infrequently performed duties as per their scope of practice. According to (Table 2), $89.9 \%$ of the time dentists never or rarely undertook any specialised dental procedures. Most visibly no Orthodontics was performed (100\%), Prosthodontics (95.4\%), Periodontics (92.6\%), Endodontics (91.7\%) and Maxillo Facial and Oral Radiology (90.3\%).

Procedures that were undertaken relatively more often to always included Maxillo Facial and Oral Surgery (12.4\%). However, these procedures were limited to suture placement and removal (33\%), drainage of abscesses (32\%), removal of impactions (14.3\%), intermaxillary fixation (13.1\%) and biopsy taking (7.6\%). Largely, CS dentists spent fractionally less time performing specialised dentistry during the CS period, which was limited to less complex Maxillo Facial and Oral Surgery procedures.

Level of clinical skills (competence) acquired during community service

According to the adapted VAS (Table 3), CS dentists did not retain their clinical skills and competence in specia-

\begin{tabular}{|c|c|}
\hline Variable & Frequency $=217 n(\%)$ \\
\hline$\leq 35$ & $151(69.7)$ \\
\hline$\geq 35$ & $66(30.3)$ \\
\hline \multicolumn{2}{|l|}{ Gender } \\
\hline Male & $90(41.3)$ \\
\hline Female & $127(58.6)$ \\
\hline \multicolumn{2}{|l|}{ Race } \\
\hline Black African & $169(78)$ \\
\hline Coloureds & $6(2.8)$ \\
\hline Indians & $25(11.4)$ \\
\hline Whites & $17(7.8)$ \\
\hline \multicolumn{2}{|l|}{ Current employment } \\
\hline Public Sector & $136(62.6)$ \\
\hline Private Sector & $49(22.8)$ \\
\hline Academic institutions & $30(13.8)$ \\
\hline Unemployed & $2(0.8)$ \\
\hline \multicolumn{2}{|l|}{ Marital status } \\
\hline Married & $47(21.7)$ \\
\hline Unmarried & $170(78.3)$ \\
\hline \multicolumn{2}{|l|}{ Year of qualification } \\
\hline 2000-2005 & $44(20.1)$ \\
\hline 2006-2010 & $86(39.7)$ \\
\hline 2011-2016 & $87(40.2)$ \\
\hline
\end{tabular}

lised dentistry during CS. For example, for the procedures that were performed most frequently, i.e. Maxillofacial and Oral Surgery, was scored, $\bar{X}(95 \% \mathrm{Cl})=1.56$ (1.44:1.69). This means the average level of skill acquired or competence developed ranged between $0-2$; that is minimal.

For other dental specialities, the levels of competence gained was equally dismal, most notably in orthodontics $=1.00(1.00: 1.01)$ and prosthodontics = 1.08 (1.03:1.13).

This indicates grave regression in the clinical skills and competence of CS dentists, when compared to the pregraduate years. Overall, the level of competence and clinical skills honed during CS was non-existent, negligible and unsatisfactory.

\begin{tabular}{|c|c|c|c|c|c|c|c|c|c|}
\hline \multirow[t]{2}{*}{ Procedures } & \multicolumn{2}{|c|}{$\mathrm{X}(95 \% \mathrm{Cl})$} & \multicolumn{7}{|c|}{ Visual Analogue Scale (VAS) } \\
\hline & & & Never/rarely & Sometimes & & Dften & & ften & Always \\
\hline Maxillofacial and Oral Surgery & \multicolumn{2}{|c|}{$1.56(1.44: 1.69)$} & 64.5 & 23.0 & \multicolumn{2}{|r|}{5.5} & \multicolumn{2}{|c|}{5.5} & 1.4 \\
\hline Maxillofacial and Oral Radiology & \multicolumn{2}{|c|}{$1.18(1.09: 1.27)$} & 90.3 & 4.6 & \multicolumn{2}{|r|}{3.2} & \multicolumn{2}{|c|}{0.5} & 1.4 \\
\hline Endodontics & \multicolumn{2}{|c|}{$1.15(1.07: 1.23)$} & 91.7 & 4.6 & \multicolumn{2}{|r|}{1.4} & \multicolumn{2}{|c|}{1.4} & 0.9 \\
\hline Periodontics & \multicolumn{2}{|c|}{$1.09(1.04: 1.14)$} & 92.6 & 6.5 & \multicolumn{2}{|r|}{0.5} & \multicolumn{2}{|c|}{0.0} & 0.5 \\
\hline Prosthodontics & \multicolumn{2}{|c|}{$1.07(1.02: 1.12)$} & 95.4 & 3.7 & \multicolumn{2}{|r|}{0.0} & \multicolumn{2}{|c|}{0.5} & 0.5 \\
\hline Orthodontics & \multicolumn{2}{|c|}{$1.00(1.00: 1.00)$} & 100 & 0.0 & \multicolumn{2}{|r|}{0.0} & \multicolumn{2}{|c|}{0.0} & 0.0 \\
\hline Overall Procedures & \multicolumn{2}{|c|}{$1.10(1.05: 1.14)$} & 91.2 & 7.8 & & 0.9 & & & 0.0 \\
\hline Procedures & $\mathrm{X}(95 \% \mathrm{Cl})$ & & & Visu & I Analogue & e Scal & AS) & & \\
\hline & & & all/minimal & Slight & Moderate & & Much & Gre & much more \\
\hline Maxillofacial and Oral Surgery & $1.55(1.43: 1.68)$ & & 65.4 & 21.7 & 6.9 & & 4.1 & & 8 \\
\hline Endodontics & $1.17(1.09: 1.25)$ & & 89.9 & 6.5 & 0.5 & & 3.2 & & 0 \\
\hline Maxillofacial and Oral Radiology & $1.18(1.10: 1.26)$ & & 89.9 & 5.5 & 2.3 & & 1.8 & & .5 \\
\hline Periodontics & $1.09(1.04: 1.14)$ & & 92.6 & 6.5 & 0.5 & & 0.0 & & .5 \\
\hline Prosthodontics & $1.08(1.03: 1.13)$ & & 94.5 & 4.6 & 0.0 & & 0.5 & & .5 \\
\hline Orthodontics & $1.00(1.00: 1.01)$ & & 99.2 & 1.4 & 0.0 & & 0.0 & & .0 \\
\hline Overall Skills Acquired & $1.10(1.05: 1.15)$ & & 91.7 & 6.5 & 1.8 & & 0.0 & & .0 \\
\hline
\end{tabular}


The results (Table 4) demonstrate highly significant positive correlation between procedures performed [Mean $(S D)=1.10$ (0.326), 1.10 (0.359); $r=0.945, p=<0.000$, $n=217]$. This finding validates the association between work not done and loss of clinical skills and competence across the specialities.

It can be concluded that the lack of clinical work in specialised dentistry might have contributed to the loss of clinical skills and competence. Community service dentists ought to be exposed to a variety of critical and complex clinical cases, in order to improve and or sustain their critical thinking, clinical skills and competence.

\section{Challenges experienced during community service}

Approximately $66.1 \%$ of CS dentists were satisfied with the placement process. Over half $(57.1 \%)$ of the participants indicated that the placement process was fair and that they were allocated to their place of preference (55.9\%). Just over half of CS dentists (53.5\%) were not satisfied with the accommodation provided.

Very few (33.9\%) CS dentists indicated that the facilities were conducive and $31 \%$ indicated that the equipment was adequate to enable effective provision of clinical services. Most dentists (54.7\%) were not supervised and almost a quarter $(24.8 \%)$ were the only dentist in the facility.

Community Service dentists reported having adequate training going into placement (84.6\%). There was a mismatch between the level of training received and type of service provision during CS. The overall perception of CS by dentists was ambivalent (49.6\%).
Association of demographic characteristics and outcomes of community service.

The frequency at which "specialised" dental procedures were performed during community services did not differ significantly with critical demographic variables. Similarly, there were no statistically significant differences in the levels of clinical skills acquired during community service based on gender, race, training institutions, site and year of community services (Table 6).

\begin{tabular}{|c|c|c|c|}
\hline & Mean (SD) & $\begin{array}{l}\text { Procedures } \\
\text { performed }\end{array}$ & $\begin{array}{c}\text { Skills/ } \\
\text { Competence }\end{array}$ \\
\hline & Period (CS) & $\mathrm{X}(\mathrm{SD})$ & $\mathrm{X}(\mathrm{SD})$ \\
\hline & (2000-2005) & $00.88(0.855)$ & $0.83(0.915)$ \\
\hline & (2006-2010) & $1.12(1.130)$ & $1.12(1.098)$ \\
\hline & (2011-2015) & $0.85(0898$ & $0.88(0.998)$ \\
\hline \multirow[t]{4}{*}{ Anova (P value) } & & $1.808 ; 2 ; 0.1664$ & $1.7299 ; 2 ; 1.000$ \\
\hline & Gender & $\mathrm{X}(\mathrm{SD})$ & $\mathrm{X}(\mathrm{SD})$ \\
\hline & Male & $0.96(0.911)$ & $0.92(0.897)$ \\
\hline & Females & $0.99(1.053)$ & $0.99(1.107)$ \\
\hline \multirow[t]{6}{*}{ Anova (P value) } & & $0.04731 ; 1 ; 0.828$ & $0.242 ; 1 ; 0.6226$ \\
\hline & Institution & $\mathrm{X}(\mathrm{SD})$ & $\mathrm{X}(\mathrm{SD})$ \\
\hline & UP & $0.95(0.952)$ & $0.93(1.003)$ \\
\hline & Wits & $0.73(0.539)$ & $0.72(0.527)$ \\
\hline & UWC & $0.87(0.881)$ & $0.84(0.962)$ \\
\hline & UL/Medunsa/SMU & $1.06(1.090)$ & $1.04(1.111)$ \\
\hline \multirow[t]{4}{*}{ Anova (P value) } & & $0.9055 ; 3 ; 0.4392$ & $0.8357 ; 3 ; 0.4756$ \\
\hline & Site of Comm Serve & $X(S D)$ & $X(S D)$ \\
\hline & Public Sector & $0.89(0.87)$ & $0.87(0.896)$ \\
\hline & Military & $3.28(1.336)$ & $3.28(1.483)$ \\
\hline Anova (P value) & & $55.6855 ; 1 ; 0.0000$ & $52.7558 ; 1 ; 0.0000$ \\
\hline
\end{tabular}

\begin{tabular}{|c|c|c|c|c|}
\hline & Frequency Procedure & Skills/Competence acquired & $\mathbf{r}$ & $\mathrm{p}$-value \\
\hline Endodontics & $0.82(1.410)$ & $0.85(1.504)$ & 0.976 & 0.00 \\
\hline Maxillofacial and Oral Surgery & $2.16(1.853)$ & $217(1,876)$ & 0.936 & 0.00 \\
\hline Maxillofacial and Oral Radiology & $0.76(1.504)$ & $0.75(1.490)$ & 0.984 & 0.00 \\
\hline Periodontics & $0.48(1.132)$ & $0.41(1.089)$ & 0.915 & 0.00 \\
\hline Prosthodontics & $0.32(0.952)$ & $0.35(1.023)$ & 0.986 & 0.00 \\
\hline Orthodontics & $0.02(0.162)$ & $0.3(0.240)$ & 0.960 & 0.00 \\
\hline Overall & $1.10(0.326)$ & 1.10 (0.359) & 0.945 & 0.00 \\
\hline
\end{tabular}

\begin{tabular}{|c|c|c|}
\hline Variables $(\mathbf{x})$ & $\begin{array}{c}\text { Yes } \\
\text { n (\%) }\end{array}$ & $\begin{array}{c}\text { No } \\
\text { n (\%) }\end{array}$ \\
\hline \multicolumn{3}{|l|}{ Placement/allocation process } \\
\hline Were you satisfied with your placement? & $143(66.1)$ & $74(33.9)$ \\
\hline Was the process of placement fair? & $124(57.1)$ & 93 (42.9) \\
\hline Were you placed where you actually wanted to be placed? & $121(55.9)$ & $96(44.1)$ \\
\hline \multicolumn{3}{|l|}{ Condition of service } \\
\hline Was accommodation provided? & $150(68.9)$ & $67(31.1)$ \\
\hline Were you happy with the accommodation? & $101(46.5)$ & $116(53.5)$ \\
\hline \multicolumn{3}{|l|}{ State of clinic readiness } \\
\hline Were the facilities conducive to provide an effective service? & $74(33.9)$ & $143(66.1)$ \\
\hline Was the equipment adequate to enable you perform your duties & $67(31.1)$ & $150(68.9)$ \\
\hline \multicolumn{3}{|l|}{ Supervision and orientation process } \\
\hline Were you oriented before your programme started? & $112(51.6)$ & $105(48.4)$ \\
\hline Were you the only dentist in the facility? & $54(24.8)$ & $163(75.2)$ \\
\hline Was clinical supervision adequate? & $119(54.7)$ & $98(45.3)$ \\
\hline \multicolumn{3}{|l|}{ Educational preparation } \\
\hline Has dental education prepared you for CS? & $184(84.6)$ & $33(15.4)$ \\
\hline Overall perception & 108 (49.6) & 109 (50.4) \\
\hline
\end{tabular}




\section{DISCUSSION}

\section{Critical assessment of validity of the results}

Two major threats affect the validity of study findings: (i) chance or random error, and (ii) bias or systematic error

\section{Role of chance}

Our study population consisted of 217 participants which is comparable to similar studies among compulsory community service in South Africa. ${ }^{6,9}$ Additionally, sample size was determined for this study in order to minimise the possibility of random error. The nature of our data analysis was simple and largely descriptive or hypothesis generating. This type of data analysis does not predispose our results to statistical error because of multiple analysis (Bonferroni correction). We can therefore conclude that our results may not be adversely affected by random error or chance, as a prerequisite for most analytical statistical analysis.

\section{Role of bias}

Bias or systematic error occurs when a single or multiple factors distort the data and ultimately the research outcomes. Bias occur due to systematic error in the design (retrospective vs. prospective vs. concurrent), conduct (selection of participants; data collection and measurements); and analysis of a study. This descriptive cross sectional study is prone to selection and recall bias. The methodology selected for this study, was meant to minimize and control these threats to validity.

(i) Selection bias: First, we incorporated records from extensive and wide range of databases to develop an inclusive and comprehensive database. In order to reach all possible participants, given missing and incomplete personal details (details, emails and cell phones numbers etc.), the snowballing technique was used to track and update the list of possible participants extending over 15 years.

The snowballing could probably result in findings that are systematically different from the population with respect to its demographics and research outcomes (objectives). If selection bias exists, it results in a lack of external validity - that is, the extent to which the study results can be generalised to the population that the sample is meant to represent. The probable difference in the demographics is valid to the extent that it affects the research outcomes (level of skills acquired; intensity of clinical work done).

The analysis of variance indicated that there are no systematic differences in the outcomes of community service by age, race, gender and other causal factors (Table 6). We could conclude that the differences in the biographical variables are not causal to the research outcomes and the results could have external validity.

(ii) Recall bias: The period of community service was regarded as the most significant factor affecting recall. We hypothesised that those who completed their community service earlier could have less recall, more so, if the events under study were less pronounced. The presence of this differential recall could invalidate the results. To minimise recall bias in design we incorporated questions from previous studies. ${ }^{6,9}$ In addition, the intensity at which procedures were done and perceived level of skills attained were assessed using a more specific scale, the VAS rather than Likert Scale. Relatively fewer dentists completed community service between $2000-2005$ (19.4\%), compared to $39.6 \%$ and $40.1 \%$ in $2006-2010$ and $2011-2015$ respectively. Therefore, the impact elapsed time on bias in our study was significantly minimal (Table 6). Overall, the study had limitations, but the results are significantly consistent to provide reliable findings, which could be cautiously generalised.

\section{Comparisons of the findings with published literature}

Since the introduction of the CS programme for medical doctors and dentists, other professional groups have lobbied for inclusion in this national programme. Notwithstanding the huge interests in the programme, anecdotal reports confirm the persistence of serious human resources and logistical challenges.

These problems have hampered the clinical development of the novice practitioners and quality of services provided. To date, no study has evaluated the impact of the CS programme on the clinical and professional development of the participating dentists. Twenty years later, this study sought to evaluate the nature and extent to which the clinical benefits are conferred to dentists during CS.

Specifically, this study assessed whether the programme provided any opportunity for the dentists to continue to hone their clinical skills and improve their clinical decisionmaking and competence following graduation. Based on the pre-graduate training and the scope of practice it is expected that dentists would during the CS year, continue to undertake the majority of clinical procedures for which they have been trained. Suffice to say that CS dentists would largely be involved in specialised dentistry to ready them for independent practice. The term "specialised dentistry" refers contextually to clinical procedures that would not be routinely performed by dental therapists or oral hygienists as per their gazetted scopes of practice. This would involve largely rehabilitative oral health services in disciplines such as maxillofacial and oral surgery, prosthodontics, orthodontics, periodontology and endodontics.

The findings indicate that over time the quality of services rendered during CS deteriorated due to poor support and limited resources. In 2002, Naidoo and Chikte ${ }^{5}$ reported that $74 \%$ of the facilities were conducive to provide oral health services. Four years on, only $65 \%$ of the services were ready. ${ }^{6}$ Fifteen years later, one in every three (33.9\%) of the practices are viable for provision of comprehensive services. This signifies a massive $55.6 \%$ attrition and decay in critical clinical infrastructure and resources. Similarly, the rate of decline was observed regarding the availability of appropriate and functional equipment; from $76 \%$ (2002) to $31.1 \%$ (2017). Due to these challenges, little or no specialised dental services were undertaken. The impact of the aging infrastructure and lack of critical armamentarium has had a devastating impact on the CS programme for dentists. 
According to the education literature, development of clinical competence is a function of lifelong structured learning process. Hence, the need for deliberate focus of competency-based education on the essentials that students must be able to do on their own, and during their early careers through continuing, self- directed and ongoing education.

According to Chambers ${ }^{11}$ competency is achieved through the transfer of learning from teachers to learners. It is only through continuing education that higher levels of competency will be achieved and sustained. Ideally, a mandatory vocational programme like CS, if well implemented should provide opportunity for novice dentists to achieve desired levels of competence. During this period, dentists would progress predictably, as they manage complex cases under strict supervision. These individuals would integrate their learning and skills in a comprehensive manner, in preparation for independent practice.

It is evident that CS in its present form disrupts continuing education and interrupts the development of learning and clinical skills. Given the minimal clinical exposure, these cohorts of dentists, are most likely to enter independent practice less prepared, yet expected to provide quality care to the unsuspecting public.

\section{Limitations of the study}

The study was undertaken over a 15-year period, which might be prone to recall bias. This shortcoming was addressed by using VAS which has more intervals (1 to $10)$, thereby allowing participants to respond with greater precision. Compared to other measures of perception or experience like the Likert scale, the VAS improves the ability to separate the signal from the noise.

Additionally, a considerable number of dentists are still in the public sector and continue to experience the same, if not, worse clinical conditions as existed during their CS years.

\section{CONCLUSION}

Based on our findings, CS for dentists is regressive, resulting in loss of clinical skills and competence. The program fails to prepare the graduates for future work in independent practice, which is a serious indictment on the programme. For the target population, the CS programme entrenches and perpetuates inequality in oral health. During undergraduate training the, indigent and deserving communities are deemed as 'interesting', 'complex' and 'available' cases. However, once in community service, the skills that are acquired by the graduates are not put to service of these communities. Paradoxically, the huge investment in training these graduates is not realised. Overall, the programme is regressive, akin to Pyrrhic victory, whichever way one looks at it.

\section{Recommendations}

In the present form, CS for dentists poses serious moral, ethical and administrative challenges. This program, while well intentioned, should be reorganised, reformed, or disbanded. To reclaim the moral, social and educational credibility, as initially intended, this program requires ge- nerous allocation of critical resources. Alternatively, the following measures should be put in place:

1. Resources - Allocation of sufficient resources (human, financial and infrastructural) are critical in ensuring that services are well run, and dentists can provide a full array of specialised dental care. In so doing, dentists will be exposed to complex cases and be able to hone their clinical skills and competencies.

2. Supervision and support - Clinical competency continuum dictates that novice dentists learn from experienced clinicians in order to improve their clinical skills and competence. Therefore, it is imperative that CS dentists are provided with adequate support and leadership when they enter the profession.

3. Radical overhaul - In line with the impending National Health Insurance (NHI) programme, the CS programme cannot continue as a dentist-centric programme. Therefore, an appropriately reformed CS programme must include all categories of oral health care workers, based on need and the services they provide in a well-structured referral system. This will provide ample opportunities for dentists to focus on the specialised dental services, while other cadres undertake preventive and restorative work.

\section{References}

1. Republic of South Africa, 1997, Medical, dental and supplementary health service professions Amendment Act, 1997 (Act No. 89 of 1997; Notice No. 1644 of 1997), Government Gazette 390 (18504), Government Printers, Cape Town. [Google Scholar].

2. Reid SJ, Conco D. Monitoring the implementation of community service. In: Crisp N, Ntuli A, editors. South African Health Review 1999. Durban: Health Systems Trust; 2000. [cited 12 September 2018]. URL:http://www.hst.org.za/publications/ South\%20 African\%20Health\%20Reviews/sahr1999.pdf.

3. Reid SJ. Compulsory community service for doctors in South Africa - an evaluation of the first year. SAMJ. 2001; 91(4): 329-36.

4. Reid S. Community service for health professionals. South African Health Review. Durban: Health Systems Trust. 2002: 135-60.

5. Naidoo S, Chikte U. Community Dental Service - the first year. SADJ. 2002; 57(5): 193-6.

6. Naidoo S. Community dental service - four years on: communication. SADJ. 2007; 62(6):250-3.

7. Reid S, Peacocke J, Kornik S, Wolvaardt G. Compulsory community service for doctors in South Africa: a 15-year review. S Afr Med J. 2018; 108(9). doi:10.7196/ SAMJ. 2018.v108i9. 13070.

8. Hatcher AM, Onah M, Kornik S, Peacocke J, Reid S. Placement, support, and retention of health professionals: National, cross-sectional findings from medical and dental community service officers in South Africa. Human resources for health. 2014; 12(1): 14.

9. Govender S, Brysiewicz P, Bhengu B. Perceptions of newly qualified nurses performing compulsory community service in KwaZulu-Natal. Curations. 2015; 38(1): 1-8.

10. Raosoft Incorporation: Raosoft Sample Size Online Calculator. 2004; (cited 2017 March 15). Available from: http://www. raosoft.com/samplesize.html.

11. Chambers D W. Dental curriculum and accreditation - means, ends, and the continuum. Dent Education. 1996; 60: 816-20.

12. Khan N, Knight S, Esterhuizen, T. Perceptions of and attitudes to the compulsory community service programme for therapists in KwaZulu-Natal. SAJCD. 2009: 56,22.

13. Calculator.net: Sample size calculator. 2008; (cited 12 Feb 2016) available from: https://www.calculator.net/sample-sizecalculator.html. 